\title{
AJMS
}

Asian Journal of Mathematical Sciences

\author{
RESEARCH ARTICLE
}

\section{A Review in Our Present Teaching Pedagogies: Traditional, Digital, and Flipped Learning}

\author{
Lam Kai Shun Carson \\ Department of Mathematics, University of Hong Kong, Pokfulam, Hong Kong
}

Received: 28-07-2021; Revised: 13-08-2021; Accepted: 20-08-2021

\begin{abstract}
There are lots of countries' government start the so called digital (e-learning) learning. In the first few sections, this author tries to analyses those barriers that prevent our schools implementing digital learning. In the following sections, this paper compares the effectiveness of traditional learning versus digital one. It shows that the class size is the detemining factor. At the same time, the flipped class model is now the newest teaching and learning pedagogy that should be focused. The result tells us that when there is a suitable teacher training, the flipped model can help students achieve higher academic achievement. This scholar believes the implementation of such model may finally come up with a better improved learning method in the future that combines of these three pedagogies. However, an improvement in our education may lead to the raise of government expenditure. The problem may finally affect various fields of spending. Thus, education becomes a political issue and may require some extra resources to fulfill the expanding needs of education manpower and her future development.
\end{abstract}

Key words: Digital, Flipped learning, Pedagogies

\section{INTRODUCTION}

Since government announced its experimental digital learning (e-learning) scheme in recent years it has been the subject of much debate. ${ }^{[1-5]}$ There is also plenty of research being done with regard to the application of digital learning, such as using online discussion forums (e.g., Moodle), for various subjects at both the primary and secondary school levels. ${ }^{[6-10]}$ However, there has been less focus on the challenges teachers have faced during implementation. Is there enough learning software for experimental physics? Are there enough technical staff on hand to help teachers overcome any IT issues during lesson preparation? These are a few of the questions that have been raised. ${ }^{[11-15]}$ If the e-learning scheme proves successful, then lessons will become much more interactive and students will become more active in class, instead of being passive. ${ }^{[16-20]}$ In other words, the quality of both teaching and learning will be improved (Henderson, 2003; Lao and Gonzales,

\section{Address for correspondence:}

Lam Kai Shun Carson

E-mail: h9361977@connect.hku.hk
2005). Naturally, during any trial phase, there will be various problems and challenges to tackle (Brzycki and Dudt, 2005; Wilson et al., 2003). ${ }^{[21-24]}$ However, by isolating any issues now, they can be fixed in time for full implementation. For example, according to Paul (2006), the key factor in the success of the scheme is capital. To overcome insufficient funding, teachers might be able to take advantage of free licensed software such as Open Office, instead of expensive ones like Microsoft Office. Since both function in a similar manner, the difference will be negligible. When the e-learning scheme is fully implemented across local schools, the whole process will therefore run much more smoothly. Failure of the trial could potentially damage the modernization of local educational system. How local teachers can be encouraged to use online discussion forums is not only interesting but also an important topic, as many schools will soon be introducing digital learning.

\section{LITERATURE REVIEW}

While previous studies of online discussion forums have highlighted the issues affecting the 
use of such technologies; first, it is important to determine how ready Hong Kong's primary and secondary school teachers are to:

1. Use new technology in the classroom

2. Integrate digital learning into their teaching; as well as

3. Establish the factors influencing their readiness.

By answering these questions, it will be possible to form some preliminary recommendations; and by subsequently acting on those recommendations it will hopefully lessen the time it will take for schools to take full advantage of modern technology.

A perfect example is Kenyan secondary schools and the impact of digital learning has had on the country's education system (Redempta and Elizabeth, 2012). The situation there can be used as a reference for the implementation of digital learning in Hong Kong's secondary schools.

A major problem for secondary schools is resistance from the non-Information and Communication Technologies (ICT) teachers in using computers in their classes (O'Neill et al., 2004). Often they feel computers are too timeconsuming and are reluctant to relinquish control of the learning environment to the students (Godfrey, 2001). Another factor might be the teachers' perceptions of the limitations of digital learning, as well as the insufficient maturity of the tools available. Resistance can also be explained by a lack of time or motivation to carry out what is basically an additional task, since digital learning is a supplement to classroombased teaching, coupled with insufficient literacy in either ICT or digital learning applications (OECD, 2005).

To determine why many teachers oppose using ICT in class through case study, the situation at Taiwanese universities was analyzed, in which the pedagogical, personal, and technological challenges faced during implementation of digital learning were revealed. Pedagogically, the concerns were over the design of new curriculum, new teaching methods, new assessments, and new interactions. Personally, concerns were to do with time management and role changes. Technologically, they were concerned with the technical skills required (Wang et al., 2008). Hence, Human Resource teachers may face similar challenges when utilizing online discussion forums.
In addition, it may require more effort from teachers to develop and maintain digital learning courses, since there are several technical issues that might hamper them. It is imperative that both students and teachers possess the necessary skills to use digital learning tools effectively. Moreover, providing support is also crucial (EDUCAUSE, 2003)

Increasingly, universities need to provide quality and flexibility to meet the diverse needs and aspirations of the students, which inevitably involves tailoring courses. Lecturers are having to fundamentally change their approach to teaching to accommodate the shift in student learning styles. This associated implication of increased workload requires proactive and effective management. Simply put, universities must change to accommodate demand and response to new competition from both global and giant corporate, and virtual universities (O'Neil et al., 2004). As such, in Hong Kong's case, both secondary schools and the teachers should take this into account before implementation of the digital learning scheme.

In practice, the key to identifying the pedagogical principles underlying the teaching and learning activities that constitute effective digital learning is to deploy an effective learning management system (Govindasamy, 2001). In other words, an effective system will encourage more non-ICT teachers to use the technology. Furthermore, it is important to regularly audit and evaluate the use of online discussion groups. This will improve the effectiveness of people's interactions and interventions (Clegg and Heap, 2008).

Research shows that while higher education staff is enthusiastic about engaging with web-based learning (WBL), they experience problems embedding the project work within their respective organizations, managing their time, and obtaining institutional recognition for their work. ${ }^{[21]}$ These findings contradict the established view that "technological illiteracy" or "technophobia" among staff is barriers to WBL implementation (Salmon and Jones, 2004). ${ }^{[22]}$

The aforementioned problems all face Hong Kong Secondary school teachers when using online discussion forums. As such, knowledge gained in tertiary education can be used at the secondary school level. Naturally, while there are differences between the two, tertiary education can act as a good reference point. However, there 
are some limitations. Several of the university lecturers stated that a significant amount of student-instructor contact occurred outside the online conferences, either through face-toface meetings during office hours or through private e-mail. Thus, only a partial picture has been obtained. Furthermore, a great deal of preparation, organization, and maintenance occurs for online courses, which has not been studied (Teles et al., 2001). All these are issues that have not been mentioned in the existing literature. If they can be resolved, then hopefully teachers will be encouraged to use technology to compensate for any disadvantages. ${ }^{[1-10]}$

The purpose of this study is to determine how secondary school teachers can be encouraged to use online discussion forums. To do so, we will study the problems and challenges they might face during implementation of such a forum [Table 1]. We will also discuss reasons why they might dislike using a forum, provide solutions, and highlight the factors which attract them. The following are the research questions that this author interesting:

1. How will digital learning motivate students to learn?

2. When will parents attempt to intervene in their children's studies?

3. What will one get if conventional teaching and learning is compared with digital?

To begin, all the problems and challenges faced by secondary school teachers when using online discussion forums should be established. Important questions to ask, for example, are: "Have they prepared well enough?" "Do they have the technical skills necessary?" "Are there enough technical staff to help them?" Once the problems have been identified, then they need to be overcome. It is important that not only are new technologies introduced but any difficulties in their application are also resolved. Moreover, to persuade teachers to adapt and change, the advantages of using new technology should be explained. By comparing situations where technology is being implemented to instances where technology has been abandoned or even not used at all, the factors influencing teachers' decisions can be practically evaluated. Not only that, but through analysis of the data, how teachers can best be helped with problem solving can be determined - all of which will improve teaching and learning; and, by association, Hong Kong's education ranking [Table 2].

\section{METHODOLOGY}

To answer the research questions, a survey consisting of a mixed research design, comprising two sections will be carried out. The first part, in the form of a questionnaire, will be handed out to both students and parents; while the second part, an interview, will focus solely on the teachers. The questionnaire, using a quantitative approach, will ask students about their use of digital equipment during their daily learning. How parents may involve in their child's studies. The interview, employing qualitative questions, will be used to compare traditional methods with digital teaching and learning methods. Using a mixed research design, a more complete picture of the situation will be constructed. Similarly, a greater number of response options for the questionnaire will result in richer data; and with the interviews, if the questions are subdivided and asked from multiple different perspectives, it will allow for the collection of more data.

\section{RESULTS AND DISCUSSION}

As this author stated in an earlierpaper(Lam, 2018), student motivation and parental involvement can result in higher academic achievement for the student. To increase their motivations rather than playing computer games and chatting online, students can use the internet, or more specifically, online discussion forums such as Moodle for learning. In addition, the relevant professionals (e.g., social workers, teachers, and principals) should have the appropriate qualifications, thereby allowing them to handle the students' non-educational ICT usage as well as any issues that may arise from this. It is important that Hong Kong has a balanced financial budget, so that local government can spend wisely and fairly between the various sectors - social, medical, culture, etc. If not, then more professionals being employed in education will result in overspending, which is unfair to others. That said, additional resources may be required for Hong Kong's education sector. The following research data support this idea. According to Lin et al. (2017), through quasiexperimentation in motivation and learning:

1. When compared to traditional methods, there are positive effects on learning motivation through digital learning. This is due to the Scheffe post hoc factor in digital learning being 
4.12, which is much greater than traditional teaching at nearly 0.8 for intrinsic orientation. In the case of extrinsic orientation, it is roughly 1.2 times greater than traditional teaching. This author believes that digital learning can intrinsically raise students' interest in learning (Lam, 2014), while suitable rewards or competitions can lead to a rise in students' extrinsic motivation (Fung, 2016 and King, 2012)

2. When compared to traditional methods, the read also positive effects on learning outcomes. The Scheffe post hoc factor in digital learning effect is increased by 0.8 , while the learning gain is 0.9 more when compared with traditional teaching methods. This author believes that when students feel passionate about learning, they are likely to spend more time studying and will work more effectively — leading to higher academic achievement. This results in better and more effective teaching, in terms of curriculum design and delivery, if they can be integrated into the digital gain through effective data usage in digital learning (Evans, 2018). Improved learning might be a result of better interaction between teachers and students, as well as having a good record of personal learning, that is, perfect personalization. Learning motivation shows positive effects on teaching effectiveness (both in learning effect and gain) in the final learning outcome. Lin et al. (2017) explains that under correlation analysis, the effect SOF intrinsic and extrinsic orientations are 2.136 and 1.838 for learning effect. At the same time, the intrinsic and extrinsic effects are 1.916 and 2.386 in terms of correlation coefficients for learning gain. Low values imply a divergence of data. This author notes that the correlation coefficient mainly concerns the slope of the best fit line before standardization in the correlation analysis. In other words, it is used to represent the linear relationship between two variables. On the other hand, the regression coefficients describe how an in-dependable variable is numerically related to a dependent variable. The group of data for learning effect is 0.202 and 0.137 intrinsic and extrinsic while 0.182 and 0.217 for learning gain correspondingly. It provides value as how much a dependent variable will increase on a unit of independent variable changes. This study shows that there is a strong correlation between learning motivation and teaching effectiveness (learning gain and effect) in digital learning. This is because of the numerous aforementioned advantages it has over traditional teaching (Lin et al., 2017). Another factor is parents' involvement in their children's ICT usage. As Grolnick (2014) explains, there are four motives that cause parental involvement:

1. External: meaning that they are "supposed to" be involved

2. Introjected: that they feel "guilty" if they are not

3. Identified: that it is important to talk with the teacher; and

4. Intrinsic: that it is fun to go to events.

Results show that the external and introjected are positively correlated; identified and intrinsic are also positively correlated; there is a possibility of guilt being evoked, such that it may cause a low level of involvement; external and introjected will create negative experiences; and schools should explain why and how parents should participate. These reasons are listed below:

A. Emotions during involvement were combined with three factors: homework, the classroom, and school, to form a positive effect index

B. Level of Involvement

1. School involvement was determined through the Parent-School Interaction Questionnaire.

2. Cognitive involvement was rated in terms of the frequency in which parents engaged in six specified activities with their children.

3. Personal involvement was measured using the parenting context questionnaire (PCQ) (Grolnick and Wellborn, 1988) — which can tell us how children's school grades and teachers' competence ratings of the children are related to PCQ.

4. Results will measure the children's perceived competence and general selfworth by using two sub-scales of the SelfPerception Profile (Harter, 1982).

5. One may obtain the children's yearly grades in reading and mathematics subjects (This author had an essay in writing about how parents may handle the conflicts between their children in ICT usage).

\section{COMPARING DIGITAL AND TRADITIONAL LEARNING}

Comparing digital learning with traditional methods can help determine its effectiveness. ${ }^{[23]}$ 
Before looking at the statistical data, it is necessary to briefly review distance learning, or the Equivalency Theorem: ${ }^{[20]}$

"Distance education's appropriate application should provide equivalent learning experiences for all students - distant and local - for them to be expectations of equivalent outcomes of the educational experience" (Simonson, 1999, p.7). ${ }^{[11-19]}$ The theorem, created by Moore in the 1970s, focuses on two areas:

1. The teacher and learner's distance between one another, or the dialog between the two

2. A measurement of the learner's autonomy, or the degree to which a program responds to the learner's needs. ${ }^{[24]}$

Normally, in traditional learning, most students depend heavily on their teacher for guidance. With digital learning, students have much more responsibility to learn on their own. This is due to there being a physical distance between the teacher and student. Hence, the more autonomy a student has, the less help they require from the teacher - they will be more responsible. In addition, the difference between the two types of learning is that conventional learning is pre-industrial.

Although, Peter in 1988 suggests that digital (distance) learning incorporates many of industrial characteristics, such as division of labor, mechanization, assembly lines, mass production, standardization, and concentration. This author, however, believes it is wrong to view education similar to industry; since each student has their own unique characteristics. This is where controversy exists with distance learning.

Indeed, digital learning does have its advantages over traditional methods, in that it (Holmberg, 1989):

1. Enhances students' motivation

2. Promotes learning pleasure

3. Allows an individual's studies to be more relevant to their specific needs

4. Creates a rapport between the learners and the institution

5. Facilities better access to the course content

6. Engages the learner with more study actives (e.g., discussion groups)

7. Allows for communication between the students.

When considering the statistical data between traditional and digital learning, Stack in 2015 shows that the most positive outcomes dominate the conventional ones. While Tittasiri in 2013 explains that both learning processes are almost identical; and, in some cases, traditional methods might outweigh digital ones. Based on Tittasiri's research, class size was the determining factor in the students' learning. Although there are differing opinions, this author believes that a well- balanced use of IT tools in schools and universities is unavoidable in the $21^{\text {st }}$ century. While the key to better teaching and learning lies in class sizes, there is no doubt that ICT can also help. Since studying from home allows for increased flexibility, is more comfortable, and is extremely convenient. To balance those conflicts between class sizes, traditional and digital learning, this author suggests one may focus on the flipped classroom pedagogy.

\section{Flipped Classroom}

Flipped classroom model is one of the most heated teaching pedagogy being experimented nowadays in various schools and universities. According to Lo in 2018, there were once a time total of 76 students from three classes who learned under three types of teaching approaches, say traditional $(n=27)$, digital learning $(n=21)$, together with the flipped one $(n=28)$. The final achievement outcome (based on the Kruskal-Wallis test) is 22.7 for the flipped class, 18.93 for the traditional, and 17.33 for the digital one. Obviously, the flipped class's academic result outweighs the other two types of learning. The reasons are (I) increased in peer interaction; (II) increased the ability to problem-solve (Lo, 2018). Indeed, from Merrill in 2002, he suggested that there are five principles in the design of the flipped classroom framework:

1. Learners are first required to solve real-world problems and are known as the "Problemcentered environment"

2. Teachers are requested to use the existing information as the basis of new materials. This is known as the "Activation Phase"

3. There will be a demonstration or explanation (according to thosenewcontents)for the learners. It is known as the "Demonstration Phase"

4. Learners will apply those new contents and are known as the "Application Phase"

5. New Knowledge is well-mixed with learner's daily world. This is our "Integration phase."

In the following page, this author will demonstrate a proposed framework of the flipped learning in Lo's 2018 pilot research. This is used by the 
author so that people may have a brief concept of the flipped.

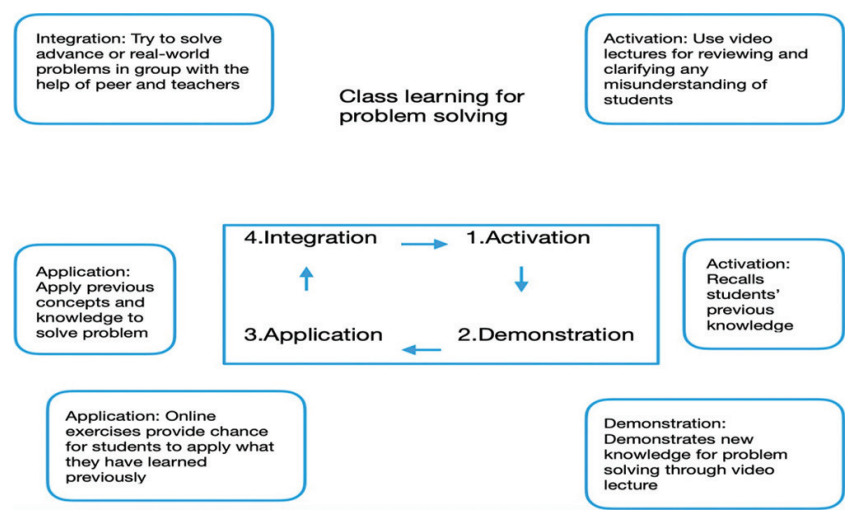

Overarching design framework of flipped learning in the pilot study (Lo, 2018, p.140).

After detailed investigations, Lo in 2018 discovered that there are six foundation principles when one tries to design a flipped course for students to learn. They are:

1. Provide ADA pre-class learning experiences; it is used to recall students' relevant preexisting knowledge, at the same time, new knowledge will be introduced through teaching videos. Each of them should be limited to $6 \mathrm{~min}$ and combined all of the segments with a maximum of time up to 20-25 min. One should use a write-whilespeaking video style. One should also provide pre-class exercises together with computerized feedback. This is used for student practice and self-checking

2. Connect pre-and in-lesson planning; Use student performance on pre-class exercises to inform the design of in-class learning activities

3. Provide a problem-problem-entered learning environment and all instructional phases in in-class learning experiences; first, one should emphasize the real-world application of course contents. The teacher will use an in-class quiz to identify and clarify students' misunderstandings. Advanced topics such as high conceptual ideas will be introduced by teachers together with answering students' queries instantly. A set of varied problems is provided. The aim is to reinforce and extend student learning. Finally, the students should be encouraged to discuss those questions that worth deep investigation, with complex or difficult knowledge and different ways of answering
Table 1: A conceptual framework of the challenges to digital learning

\begin{tabular}{|c|c|c|}
\hline Categories & Student & Teacher \\
\hline \multicolumn{3}{|l|}{ Individual } \\
\hline & $\begin{array}{l}\text { - Motivation } \\
\text { - Academic confidence } \\
\text { - Technological } \\
\text { confidence } \\
\text { - Social support (support } \\
\text { from home and } \\
\text { employers) } \\
\text { - Gender } \\
\text { - Age }\end{array}$ & $\begin{array}{l}\text { - Technologic al } \\
\text { - } \text { Confidence } \\
\text { - Motivation and } \\
\text { commitment } \\
\text { - Qualification and } \\
\text { competence } \\
\text { - Time }\end{array}$ \\
\hline Course & Course design & Support provided \\
\hline & $\begin{array}{l}\text { - Curriculum and subject } \\
\text { content } \\
\text { - Teaching and learning } \\
\text { activities }\end{array}$ & $\begin{array}{l}\text { - Support for students } \\
\text { from faculty } \\
\text { - Support for faculty }\end{array}$ \\
\hline Contextual & Organizational & Social/Cultural \\
\hline & $\begin{array}{l}\cdot \text { Knowledge } \\
\text { - Management economy } \\
\text { - And funding }\end{array}$ & $\begin{array}{l}\text { - Role of teacher and } \\
\text { student } \\
\text { - Attitudes on digital } \\
\text { learning and IT }\end{array}$ \\
\hline Technological & $\begin{array}{l}\text { - Training of teachers and } \\
\text { staff } \\
\text { - Access } \\
\text { - Cost } \\
\text { - Software and interface design } \\
\text { - Localization }\end{array}$ & - Rules and regulations \\
\hline
\end{tabular}

4. Provide choices in flipped learning; more types of learning materials should be available for students so that they can choose their learning tasks and hence form their groups

5. Facilitate peer interactions; Use peer-assisted learning models such as peer instruction

6. Foster ability through teacher feedback; Try to identify those concepts and skills involved in problem-solving exercises.

This author notes that the first three principles are used for supporting student learning in flipped courses. While the latter three are applied for supporting student engagement in flipped learning. To sum up, in a normal situation (with a trained teacher), flipped learning seems to be more effective for our students to attain maximum academic achievement. It is likely to be the best pedagogical practice among traditional and digital (online) learning in our modern education until now from such perspective. However, there are still disadvantages such as it requires internet access at home, good organization and lots of motivation to be well-prepared before lessons. All these are factors that need to be considered before widely implemented. This author still thinks that it would be feasible and worth to be carried out in our local schools and universities as a new stimulus to our present education system. This 
Table 2: Digital learning rankings by category (The Economist, 2003)

\begin{tabular}{lccccc}
\hline Sweden & Education & Industry & Government & $\begin{array}{c}\text { Society } \\
\text { Over all } \\
\text { rank }\end{array}$ \\
\hline Canada & 2 & 3 & 14 & 6 & 2 \\
USA & 1 & 1 & 22 & 1 & 3 \\
Finland & 9 & 5 & 2 & 5 & 4 \\
South Korea & 4 & 1 & 16 & 12 & 5 \\
Singapore & 11 & 7 & 25 & 4 & 6 \\
Taiwan & 13 & 9 & 20 & 17 & 16 \\
Hong Kong & 20 & 13 & 32 & 24 & 23 \\
Japan & 24 & 22 & 28 & 32 & 25 \\
Malaysia & 27 & 15 & & \\
\hline
\end{tabular}

author suggests there should be an integration of traditional learning with a digital one that combines with the small grouped size in problemsolving. While, traditional learning is for a brief theory introduction as a means of motivation to learn online (in a digital way). Later, at home, pupils are required to understand in-depth and prepare for the coming flipped class problemsolving. During the flipped class, they are needed to apply those learned for solving related daily issues. This is evolved from the three teaching pedagogies for the well-learning of our future students. This author named the above proposed one as the "Mixed" pedagogy.
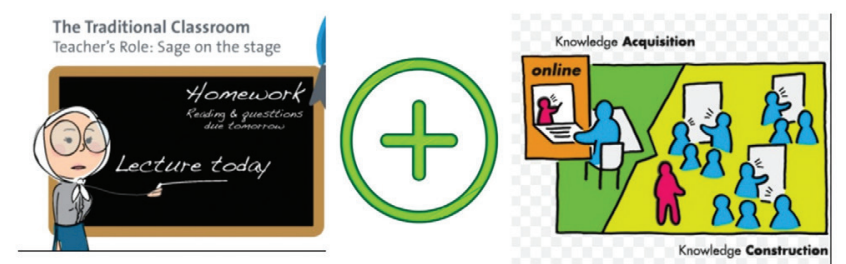

A new learning pedagogy that combines of traditional, digital and flipped learning (Photos downloaded from Google image).

\section{CONCLUSION}

Smaller class sizes can increase the effectiveness of teaching and learning especially when the flipped classroom is implemented in our education. However, it could lead to an increase in manpower and the need for various types of digital equipment. Ultimately, the result is an increase in financial expenditure for the education sector. As such, economic and financial factors also play a part when it comes to education. Moreover, if local government wants to implement digital learning or even a flipped classroom for the better student learning result, together with increasing parental involvement, there will also be a greater demand in manpower. Then the outcome is an influence to the final amount of government spending or a greater finance expenditure. Therefore, the question of education is quite political. To maintain equilibrium with other sectors, such as social, medical, and cultural, it is likely that additional resources will be required to support a greater educational expenditure. The situation becomes even worst when both the small class sizes or flipped class and those aforementioned human requirements for students' ICT usage were implemented in the future. In the end, if our local educational budget can spend wisely in teaching and learning with supplementary external funding, it will increase the effectiveness of the educational system and fulfill our society's needs.

\section{REFERENCES}

1. Anderson A, Gronlund A. A conceptual framework for E-learning in developing countries: A critical review of research challenges. Electron J Inform Syst Dev Ctries 2009;38:16.

2. Brzycki D, Dudt K. Overcoming barriers to technology use in teacher preparation programs. J Technol Teac Educ 2005;13:619-41.

3. Clegg P, Heap J. Facing the Challenge of E-learning: Reflections on Teaching Evidence-Based Practice Through Online Discussion Groups; 2008. Available from: http://citeseerx.ist.psu.edu/viewdoc/ download?doi=10.1.1.186.4493\&rep=rep1\&type=pdf.

4. EDUCAUSE Center for Applied Research, Impact and Challenges of E-Learning. Available from: https:// library.educause.edu/ /media/files/library/2013/6/ ers1304.pdf?la=en.

5. Evans C, Howson CK, Forsythe A. Making sense of learning gain in higher education. High Educ Pedagog 2018;3:1-45.

6. Fung W. A Study on Intrinsic Motivation, Extrinsic Motivation, Reading Efficacy, Reading Motivation in Relation to the Reading Competency of Top-Performing and Low-Performing Primary Students in Hong Kong: 
A Gamified Reading Perspective; 2016. Doi: http:// dx.doi.org/10.5353/th b5812679.

7. Godfrey C. Computers in schools: Changing pedagogies. Aust Educ Comput 2001;16:16.

8. Govindasamy T. Successful Implementation of E-Learning Pedagogical Considerations; 2001. Doi: 10.1016/S1096-7516(01)00071-9.

9. Grolnick W. Mothers' Motivation for Involvement in Their Children's Schooling: Mechanisms and Outcomes. Berlin, Germany: Springer; 2015.

10. (a) Henderson AJ. The E-Learning Questions and Answer Book. New York: Amacom; 2003.

(b) Holmberg B. Theory and Practice of Distance Education. London: Routledge; 1989.

11. Lam KS. Encouraging Statistical Learning Through Eastern and Western Mathematical History and Its Butterfly Effect Consequences; 2018. Available from: https://www.ssrn.com/abstract=3280934. Doi: http:// dx.doi.org/10.2139/ssrn.3280934.

12. Lao D, Gonzales D. Understanding online E-learning through a qualitative description of professors and students' experiences. J Technol Educ 2005;13:459-74.

13. Lin MH, Chen HC, Liu KS. A study of the effects of digital learning on learning motivation and learning outcome. Eurasia J Math Sci Technol Educ 2017;13:3553-64.

14. Lo C. Flipped Learning with Gamification in Secondary School Mathematics Education: A Study of Student Achievement and Engagement, Thesis, University of Hong Kong, Pokfulam, Hong Kong SAR; 2018. Available from: http://hdl.handle.net/10722/264803.

15. OECD. E-Learning in Tertiary Education: Brief Policy. Paris, France: OECD; 2005. Available from: http:// www.oecd.org/dataoecd/55/25/35961132.pdf. [Last accessed on 2007 Jun 25].

16. O'Neil K, Singh G, O'Donoghue J. Implementing E-Learning Programmes for Higher Education: A Review of the Literature. Wolverhampton, UK: University of Wolverhampton; 2004.

17. Justice P. The Challenges of Implementing E-Learning; 2006. Available from: http://www.cedma-europe. org/newsletter $\% 20$ articles/Just $\% 20$ learn/the $\% 20$ challenges $\% 20$ of $\% 20$ imlementing $\% 20$ e-learning $\% 20$ (jan\%2006).pdf. Doi: 10.1186/s41239-016-0034-x.

18. Redempta K, Elizabeth M. An E-learning approach to secondary school education: E-readiness implications in Kenya. J Educ Pract 2012;3:142-8.

19. Salmon D, Jones M. Higher education staff experiences of using web-based learning technologies. J Educ Technol Soc 2004;7:107-14. Doi: 10.1.1.96.3222\&rep $=$ rep $1 \&$ type $=p d f$.

20. Simonson M, Schlosser C, Hanson D. Theory and distance education: A new discussion. Am J Distance Educ 1999;13:60-75.

21. Sofiadin AB. Development and Evaluation of a Sustainable E-Learning Framework for Higher Education Institutions in Malaysia, Curtin University; 2018.

22. Teles L, Ashton S, Tzoneva I. The Role of the Instructor in E-Learning Collaborative Environments. Burnaby, Canada: Simon Fraser University; 2001.

23. Titthasiri W. A Comparison of E-Learning and Traditional Learning: Experimental Approach. International conference on Mobile Learning, E-Society and E-Learning Technology-Singapore; 2013.

24. Evans C, Kandiko Howson A. Forsythe (2018) Making sense of learning gain in higher education, Higher Education Pedagogies, 3:1:1-45. 